\title{
The Epidemiological Hypothesis Of "The Trojan Horse": Were Hospitals The Main Vectors Of The Exponencial Beginning Of Coronavirus Disease 2019 (Covid-19) In Spain And Other Countries?
}

\section{Turabian JL*}

Specialist in Family and Community Medicine, Regional Health Service of Castilla la Mancha (SESCAM), Spain

*Corresponding author: Jose Luis Turabian, Health Center Santa Maria de Benquerencia. Regional Health Service of Castilla la Mancha (SESCAM), Toledo, Spain, E-mail: jturabianf@ hotmail.com

\section{Commentary}

Volume 4 Issue 3

Received Date: April 15, 2020

Published Date: May 08, 2020

DOI: $10.23880 /$ eij-16000146

\section{Abstract}

Experience has highlighted the ineffectiveness of hospitals as the first port of call for viruses. This article, based mainly on the case of Spain, proposes to reflect on two hypotheses: 1) the main cause of the explosive increase in the coronavirus disease 2019 (COVID-19) outbreak was hospitals: Initially, under poor epidemiological information systems, a number of "imported" cases circulated in the community weeks before the outbreak of COVID-19. Symptomatic cases were treated in the health system, both in health centers and in hospital emergency services. The most serious cases came to hospitals. COVID-19 entered camouflaged as "usual" acute respiratory infections, as in a Trojan horse. Once COVID-19 was "activated" within hospital (a closed institution where hundreds or thousands of people live closely with each other and with their sick and relatives), the virus was "installed" in doctors, nurses, auxiliary personnel, ambulance drivers, etc., as well as other patients, all of this exponentially and in a very short time fast, crashing the system. And 2) The main cause of the maintenance of the COVID-19 outbreak is Nursing homes and even hospitals: The fact of maintaining relatively high numbers of new cases and deaths after three weeks of mandatory confinement, should be mainly due to the new cases of contagion in Nursing homes, and the maintenance of contagions in hospitals overflowing, poorly conditioned, saturated with sick, and with still limited protective equipment.

Keywords: COVID-19; Epidemiology; Infectious Disease; Outbreak Modelling

\section{Abbreviations: COVID-19: Coronavirus Disease} 2019; SARS-Cov-2: Severe Acute Respiratory Syndrome Coronavirus 2; GPs: General Practitioners; PCR: Polymerase Chain Reaction.

\section{Introduction}

The current outbreak of coronavirus disease 2019
(COVID-19), caused by the severe acute respiratory syndrome coronavirus 2 (SARS-CoV-2), which was first detected in Wuhan, China, in December 2019, continues to spread affecting many countries and territories around the world, and WHO having declared it a pandemic on March 11, $2020[1,2]$. Its figures are rapidly changing, and when this is written, as of April 11, 2020, the pandemic has infected more than 1,700,000 people and killed more than 103,000 


\section{Epidemiology International Journal}

worldwide; The United States has more than 500,000 cases, followed by more than 159,000 in Spain, and more than 147,000 in Italy, which have overtaken China in the total number of COVID-19 cases [3].

In this scenario, COVID-19 pandemic raises many questions. One of them is the reflection on the cause of the initial exponential outbreak, and later the cause of the maintenance of a certain plateau of cases after the descent of the curve. This short article, which is a personal view, based on an unsystematic or opportunistic search for information and the author's experience. It is intended to underline a hypothesis that answers those questions about the rapid and exponential initial increase in the incidence of COVID-19 cases in many countries, and the maintenance of this incidence in average figures despite the curentena measures, based on the case of Spain.

\section{Discussion}

The COVID-19 began to spread from Wuhan in Hubei province in late 2019. As in many parts of China, Wuhan is a hospital-oriented health service, as the family medicine system is not yet fully implemented. The increase in patients to hospitals quickly overwhelmed the health system in Wuhan and the surrounding towns and cities, as patients sought tests and treatment, and in the process helped spread the virus more quickly. Experience has highlighted the ineffectiveness of hospitals as the first port of call for this and other types of viruses [4].

\section{Hospitals (And Health Centers) Can Become Vectors of Infection}

Hospitals and health centers (to a lesser extent) can become vectors of infection from patient to patient within the center itself and transmit the infection to the community, in addition to affecting to the health personnel itself [5]. Airborne or aerosol transmission, more than two meters, is believed to occur in COVID-19 during invasive medical procedures of the respiratory tract. During the outbreak of severe acute respiratory syndrome (SARS) in 2003, the presence of the virus in the air of the rooms of hospitalized patients was already confirmed [6]. The nature of the job puts healthcare workers at an increased risk of contracting any communicable disease, including COVID-19. During the SARS outbreak in 2002, a fifth of all cases were in health workers $[7,8]$.

COVID-19 sufferers began arriving at hospitals and GPs offices little by little, but in a couple of days they multiplied in incalculable quantities. The crisis unleashed by the coronavirus has been especially difficult for health workers to manage because it has confronted them with their worst enemy: uncertainty. What happens in the hospital, at another level also happens in general medicine: for general practitioners (GPs) it is very uncomfortable to find that patients with a respiratory infection, that they do not know how to catalog or treat [9]. On the other hand, there has been an evident lack of protective material in health centers [10].

Some reasons for such a high number of infected healthcare workers during the beginning of the emergency outbreak can be: 1) inadequate personal protection of healthcare workers at the beginning of the epidemic. In fact, they did not understand the pathogen well; and their awareness of personal protection was not strong enough. Other reasons for consultation could be seen in asymptomatic patients but with COVID-19, or they could be paucisymptomatic patients, and there was no feeling of danger in the first moments. Therefore, the front-line healthcare workers did not implement the effective personal protection before conducting the treatment; 2) long-time exposure to large numbers of infected patients directly increased the risk of infection for healthcare workers. Also, pressure of treatment, work intensity, and lack of rest indirectly increased the probability of infection for healthcare workers; and 3) shortage of personal protective equipment was also a serious problem [11]. In addition, in Spain, the guidelines of not performing the diagnostic test for COVID-19 in people with a clinical picture of mild acute respiratory infection in the community, increases distress in all primary care personnel who do not know the disease and the patient's risk who is attending [9].

\section{High Proportion of Healthcare Workers with COVID-19}

The high number of infected healthcare professionals in Spain, which with 23,609 cases until April 9, 2020, and with a number of reported cases in Spain for that day of 152,446, represents $15 \%$ incidence, creates a scenario atypical, dangerous and stressful for the professionals themselves, and a significant risk for the general population [12-14].

In the area where the author works, a peripheral neighborhood of Toledo (Castilla La Mancha, Spain), with 20,000 inhabitants and as of April 7, 2020, there were 95 confirmed cases of COVID-19 confirmed with polymerase chain reaction (PCR), from of which 31 (33\%) were health or nursing home professionals or health center workers, that is, 1 in 3 confirmed cases. It should be borne in mind that: 1) on the one hand, that the failure to perform the diagnostic test on patients with mild respiratory symptoms in the community in Spain (since the instructions are, to the date of writing this text, that diagnostic test for SARS-CoV-2 be performed at people with a clinical picture of acute respiratory infection admitted to the hospital, or respiratory infection of any 


\section{Epidemiology International Journal}

degree in health personnel. Similarly, routine diagnostic tests are not performed on contacts), which may mean more PCR done in health professionals than in the general population, so that the number of sick health professionals is proportionally overestimated; and 2) that this figure of 33\% of sick health professionals does not include quarantined health professionals for contact with cases, which are many more [9].

This situation suggests the magnitude of the problem of infections in hospitals and health centers, and later in nursing homes and other community health centers. it should be noted the large number of people who work in them: the latest available data from the Ministry of Finance in Spain reveal that the workers of the National Health System totaled 515,000 at the beginning of the year, to which we should add those who are working in private health and in the social and health sector; in total, about 1.5 million people, to which should be added the elderly residents and hospitalized patients, and their respective social and family environments [14].

A similar situation has been reported in Italy, where Italy's healthcare workers sacrificing their health in the battle to combat COVID-19 lack sufficient protective equipment to keep them safe, as well as in other European countries $[15,16]$. It is estimated that one out of every 20 patients admitted to a hospital will contract an infection, simply because they are hospitalized. In addition, it would be necessary to consider the risk of contagion of patients' companions in the waiting rooms of the emergency service, or of external consultations, in the use of common hospital areas such as cafeteria, rest areas, toilets, etc., and during visits to hospitalized patients. All the different categories of personnel working in the healthcare environment are exposed, with greater risk than the general population, to contracting infections or transmitting them to other people and patients [17].

\section{The case of Spain: chronology of COVID-19 in Spain}

The health authority in Spain spoke for the first time of suspected cases of COVID-19 on January 25, 2020, but it was confirmed that they had given negative. The first infected was confirmed on the 31st of that month (an imported case). On February 10 there was another case also imported. The Health Authority affirmed on February 23: "In Spain there is neither a virus nor is the disease being transmitted." On February 25, the "third case", also imported, was detected. However, on February 26 the first native infected person was known, a 62-year-old man who had not traveled to any risk area. "The virus has been circulating in Spain for several days and we had not detected it," explained the head of the infectious diseases department of a large hospital that day. The first death was known on March 4: a 69-year-old man who had died on February 13 and in whom COVID-19 had been detected in a subsequent autopsy. On March 9 there were already 1,200 confirmed cases, more than double the previous day, with 28 deceased, and it was assumed that "obviously there was some kind of community transmission" [18].

\section{GPs, Health Centers and CoVOID-19}

It has been estimated at 900,000 the number of cases with a clinical picture of COVID-19, with mild symptoms and without confirmation that GPs have attended in Spain, and that they have not been mostly referred to hospitals [19]. Based on a survey, the Spanish Society of Family and Community Medicine estimated 65,149 positive cases for COVID-19 that was being monitored by health centers. This figure is close to the 64,059 positive cases officially reported by the Spanish Ministry of Health on those same dates (March 27). Thus, it was calculated that each GP controls two people diagnosed with COVID-19 and 36 people who we suspect [20]. Other authors had calculated similar figures, which could be between 26 and approximately 40 hidden real cases in each Spanish general medicine consultation, as of April 9, $2020[9,21]$.

In Spain, at the date of writing this article, April 11, 2020, the diagnostic test is not performed in patients with mild respiratory symptoms in the community [9]. In this way, GPs have been hit hard, both in Spain and in Italy and other countries, acting as a first line to identify patients with symptoms that suggest COVID-19. And they are paying a heavy price for a lack of training, the right tools, and the right plan [22,23]. As of April 1, 24 active healthcare professionals had died of COVID-19 throughout Spain. To get a comparative idea, the case of the first active doctor killed by COVID-19 in South Korea (and probably the only one) was published on April $3[24,25]$.

\section{Long-term care facilities / Nursing homes}

Long-term care facilities and Nursing Homes are high-risk settings for severe outcomes from outbreaks of COVID-19, owing to both the advanced age and frequent chronic underlying health conditions of the residents and the movement of health care personnel among facilities in a region [26]. In this sense, the model of Nursing Homes, and also for people with disabilities has become during the COVID-19 pandemic into real death traps. A model based on the concentration of risk groups in small spaces, with low quality standards and insufficiently prepared, that cannot cope with an epidemic like the one we are experiencing, must be completely reformulated. In this way, the cost in 


\section{Epidemiology International Journal}

lives that the current model of nursing homes in Europe and America, at least, will suppose will be very important and hardly affordable [27]. The maintenance of moderately high numbers of new cases of COVID-10 and deaths, after three weeks of mandatory confinement in Spain, is probably due mainly to the cases in the Nursing Homes.

\section{The Trojan horse}

The Trojan horse is a story from the Trojan War about the subterfuge that the Greeks used to enter the independent city of Troy and win the war. In the canonical version, after a fruitless 10-year siege, the Greeks constructed a huge wooden horse and hid a select force of men inside, including Odysseus. The Greeks pretended to sail away, and the Trojans pulled the horse into their city as a victory trophy. That night the Greek force crept out of the horse and opened the gates for the rest of the Greek army, which had sailed back under cover of night. The Greeks entered and destroyed the city of Troy, ending the war. Metaphorically, a "Trojan Horse" has come to mean any trick or stratagem that causes a target to invite a foe into a securely protected bastion or place [28].

It must probably be thought that hospitals and health centers (to a lesser extent), and Nursing homes, are "biological bombs" that act as vectors of disease. It was already known that above a certain threshold, or in certain circumstances, health care can be iatrogenic [29]. The COVID-19 pandemic tragically reminds us of this. For example, we are learning that hospitals might be the main COVID-19 carriers, as they are rapidly populated by infected patients, facilitating transmission to uninfected patients, to health professionals and their families and social contacts. Since the concentration of cases and people is very high in hospitals, even in the early stages of an infectious outbreak with asymptomatic (undiagnosed) but contagious patients, and in conditions of absence of protective measures, with total lack of isolation (actually with a high degree of personperson aggregation), the hospital becomes a "biological bomb" and justifies the explosive increase in the COVID-19 outbreak in many areas of Spain. In addition, it must be taken into account, that patients are transported by health regional system, which also contributes to spreading the disease as its ambulances and personnel rapidly become vectors. So, health workers are asymptomatic carriers or sick without surveillance [30].

Thus, in addition to detecting sick healthcare workers, it is recommended that a practice area (a connected building or temporary structure) be designated as a "respiratory virus assessment center" during the COVID-19 epidemic. And probably similar architectural and organizational recommendations, such as separating healthy from sick, or possible infectious patients, etc., will also be useful for the future both in hospitals and in community health centers. Another type of hospital is necessary [31,32].

\section{Epidemiological information systems}

The COVID-19 outbreak did not stem from an explosive event that appeared out of nowhere, at the Huanan seafood wholesale market in Wuhan, China, but could have originated elsewhere and probably involved more than one zoonotic spillover [33]. Almost $80 \%$ of the cases diagnosed (documented) in China before the confinement by COVID-19 started on January 23 would have been infected by undocumented cases (not known), for having little or no symptoms. The authors estimate that undocumented cases were less contagious than documented (diagnosed) cases, but since they were many more, they were the source of contagion for the vast majority of documented cases. Even in early phase of the COVID-19 pandemic, several studies have now strongly indicated asymptomatic and presymptomatic transmission of the virus in several cases. [34-41]. Therefore, one of the lessons that this crisis will leave is the need for better information management systems. Health authorities must multiply their capacity to collecting, process and disseminate statistical information [32].

\section{Implications for future interventions}

Putting the focus here and adopting the necessary control measures will be decisive for the future of the epidemic in Spain. But, the immunological situation of healthcare staff is still not well known due to the lack of tests. Probably the way is to test all personnel to detect IgG and IgM antibodies and, depending on that, to do or not to perform PCR. It is important to know which professionals have passed the infection so that they can safely attend to patients, who in hospitals tend to have a risk profile. The performance of tests is mandatory also in all closed groups, from nursing homes to prisons. And, once the results are known, the different groups must be separated with all the precise measurements [14]. On the other hand, in hospitals and health centers, must change their architecture, organization and use, to minimize the effect of "Trojan horse"

\section{Conclusion}

Of course, many epidemiological factors in the analysis of the causes of the exponential increase in the COVID-19 outbreak in Spain and other countries must be taken into account, such as the fact that the more urban density there is, the greater the risk of explosive transmission exists, so that large cities are risk bombs, must be taken into account. But in Spain the infection has affected to an extent as intense or more in areas with little population, such as Castilla-La Mancha, whose capital, Toledo, is where the author works. This article emphasizes the hypothesis that: 


\section{Epidemiology International Journal}

- The main cause of the explosive increase in the COVID-19 outbreak was hospitals: Initially, under poor epidemiological information systems, a number of asymptomatic or paucisymptomatic and symptomatic "imported" cases circulated in the community weeks before the outbreak of COVID-19. Symptomatic cases were treated in the health system, both in health centers and in hospital emergency services. The most serious cases of COVID-19, mainly pneumonia, came to hospitals (and patients were admitted) camouflaged as "usual" acute respiratory infections (although they probably could not be ascribed to any pathogen, including major viruses such as influenza, etc.). Once COVID-19 was "activated" within the health system, mainly hospital (a closed institution where hundreds or thousands of people live closely with each other and with their sick and relatives, the virus was "installed" in doctors, nurses, auxiliary personnel, ambulance drivers, etc., as well as other patients, and later on other support or administrative personnel of the health system, as well as relatives of patients and health personnel, all of this exponentially and in a very short time fast, crashing the system.

- The main cause of the maintenance of the COVID-19 outbreak is the homes of the elderly and even hospitals: The fact of maintaining relatively high numbers of new cases and deaths after three weeks of mandatory confinement of the whole society, should be mainly due to the new cases of contagion in Nursing Homes (and to a lesser extent of other closed institutions), and the maintenance of contagions in overflowing, poorly conditioned, saturated with sick hospitals, and with still limited protective equipment.

\section{References}

1. Zhu N, Zhang D, Wang W, Li X, Yang B, et al. (2020) A novel coronavirus from patients with pneumonia in China, 2019. N Engl J Med 382(8): 727-733.

2. García-Basteiro $\mathrm{AL}$, Chaccour $\mathrm{C}$, Guinovart $\mathrm{C}$, Llupià $\mathrm{A}$, Brew J, et al. (2020) Monitoring the COVID-19 epidemic in the context of widespread local transmission. Lancet Respir Med: 1-3.

3. Coronavirus COVID-19 Global Cases by the Center for Systems Science and Engineering (CSSE) at Johns Hopkins. The Center for Systems Science and Engineering (CSSE) at JHU.

4. Li DKT, Zhu S (2020) Contributions and challenges of general practitioners in China fighting against the novel coronavirus crisis. Family Medicine and Community Health 8: 000361.
5. Infection Control. How Infections Spread (2016) CDC.

6. Booth TF, Kournikakis B, Bastien N, Ho J, Kobasa D, et al (2005) Detection of Airborne Severe Acute Respiratory Syndrome (SARS) Coronavirus and Environmental Contamination in SARS Outbreak Units. Int J Infect Dis 191(9): 1472-1477.

7. Chan-Yeung M, Xu RH ((2003) SARS: epidemiology. Respirology 8 (Suppl): 9-14.

8. Wetsman N (2020) Health care workers are at high risk of catching COVID-19. If they get sick, it's bad for everyone. The Verge.

9. Turabian JL (2020) Micro-Impact of the Pandemic by Covid-19 in the General Medicine: Clinical and Epidemiological Reflections from the Situation in Spain March 2020. Epidemol Int J 4(2): 1-11.

10. Cotelo J (2020) Coronavirus verticalizes its curve by overflowing the system and hitting its healthcare professionals. Medscape.

11. Wang J, Zhou M, Liu F (2020) Reasons for healthcare workers becoming infected with novel coronavirus disease 2019 (COVID-19) in China. J Hosp Infect: 1-2.

12. Nieto Martínez C (2020) Overexertion, fear of contagion, and anxiety: emotional effects of COVID-19 in Spanish doctors. Medscape.

13. Coronavirus (COVID-19) Departamento de Seguridad Nacional.

14. Güell O (2020) Residencias y hospitales concentran los nuevos contagios por coronavirus. El confinamiento convierte a los centros sanitarios y de mayores en el reducto de la enfermedad. El País.

15. International Council of Nurses (2020) High proportion of healthcare workers with COVID-19 in Italy is a stark warning to the world: protecting nurses and their colleagues must be the number one priority.

16. Minder R, Peltier E (2020) Virus Knocks Thousands of Health Workers Out of Action in Europe. New York Times.

17. Acosta-Gnass SI (2011) Infection control and hospital epidemiology manual. Washington: Organización Panamericana de la Salud. WHO.

18. Medina MA (2020) Chronology of the coronavirus epidemic in Spain in just a month and a half. El País.

19. Sociedad Española de Medicina Familiar y Comunitaria (2020) The semFYC quantifies in close to a million those 


\section{Epidemiology International Journal}

affected by a clinical picture of COVID-19 in Spain, with more than 900,000 mild and without tests attended in Primary Care. SemFYC.

20. Mouzo J (2020) Primary care estimates that 2\% of the population has symptoms of Covid-19. El País.

21. Turabian JL (2020) Clinical-epidemiological characteristics that may help the general practitioner to consider COVID-19 diagnosis in acute respiratory infections when diagnostic tests are not accessible. Epidemol Int J 4(2): 1-10.

22. Ovadia D (2020) COVID-19: What Can the World Learn From Italy?. Medscape.

23. Frellick M (2020) Colleagues Mourn Italian 'Hero' Physician Killed by COVID-19. Medscape.

24. 1st doctor death from coronavirus in S. Korea (2020). The Korea Times.

25. Simó J (2020) Active healthcare professionals deceased by covid-19 in Spain: more than one a day.

26. McMichael TM, Currie DW, Clark S, Pogosjans S, Kay M, et al. (2020) Epidemiology of Covid-19 in a Long-Term Care Facility in King County, Washington. N Engl J Med: 1-7.

27. Roldán D (2020) The control of nursing homes is vital so as not to saturate the system. Sábado.

28. Trojan Horse.

29. Illich I (2003) Medical nemesis. J Epidemiol Community Health 57: 919-922.

30. Nacoti M, Ciocca A, Giupponi A, Brambillasca P, Lussana F, et al. (2020) At the Epicenter of the Covid-19 Pandemic and Humanitarian Crises in Italy: Changing Perspectives on Preparation and Mitigation. N Engl J Med: 1-5.

31. Sikka N (2020) How to Start Doing Telemedicine Now (In the COVID-19 Crisis). Perspective. Medscape Business of
Medicine.

32. Turabian JL (2020) Medical Concepts with ClinicalEpidemiological Implications that have to be ReAssessed Since the Coronavirus Disease 2019 (Covid-19) Pandemic. International Journal of General Practice (1): 17-27.

33. Zhang X (2020) Epidemiology of Covid-19. N Engl J Med: $1-2$.

34. Bai Y, Yao L, Wei T, Tian F, Jin DY, et al. (2020) Presumed Asymptomatic Carrier Transmission of COVID-19. JAMA 323(14): 1406-1407.

35. Rothe C, Schunk M, Sothmann P, Bretzel G, Froeschl G, et al. (2020) Transmission of 2019-nCoV Infection from an Asymptomatic Contact in Germany. N Engl J Med 382: 970-371.

36. Hu Z, Song C, Xu C, Jin G, Chen Y, et al. (2020) Clinical characteristics of 24 asymptomatic infections with COVID-19 screened among close contacts in Nanjing, China. Sci China Life Sci.

37. Han Y, Yang H (2020) The transmission and diagnosis of 2019 novel coronavirus infection disease (COVID-19): A Chinese perspective. J Med Virol 92(6): 639-644.

38. Wei WE, Li Z, Chiew CJ, Yong SE, Toh ME, et al. (2020) Presymptomatic transmission of SARS-CoV-2Singapore. MMWR Morb Mortal Wkly Rep 69(14): 411415.

39. Fais E (2020) Coronavirus. Asintomatici, il virologo: «Se continuiamo a mandarli in giro l'epidemia non la elimineremo mai». El Gazzettino.it.

40. Cereda D, Tirani M, Rovida F, Demicheli V, Ajelli M, et al. (2020) The early phase of the COVID-19 outbreak in Lombardy, Italy. ArXiv.

41. Simó J (2020) The first not true of the coronavirus pandemic. Salud, dinero y atención primaria. 